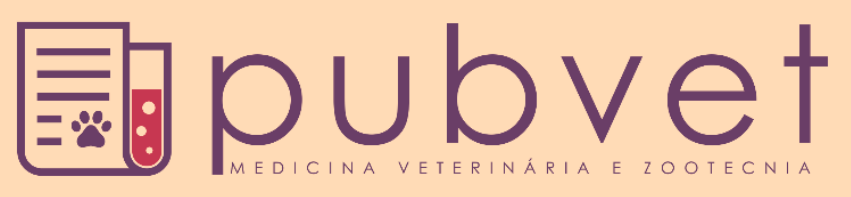

https://doi.org/10.31533/pubvet.v15n08a881.1-13

\title{
Contenção química e física de répteis: Revisão
}

\author{
Rochelle Gorczak $^{1 *} \bullet$, Maria Eduarda $\operatorname{Tronco}^{2}{ }^{\bullet}$, Marilia Avila Valandro ${ }^{1} \bullet$ (D), Bruna

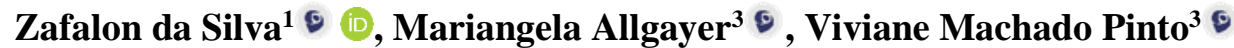 \\ ${ }^{I}$ Professora do Centro Universitário Ritter dos Reis - UniRitter, Faculdade de Medicina Veterinária, Porto Alegre-RS, Brasil. \\ ${ }^{2}$ Médica Veterinária Autônoma, Porto Alegre, RS, Brasil. \\ ${ }^{3}$ Professora da Universidade Luterana do Brasil - ULBRA, Faculdade de Medicina Veterinária, Canoas-RS, Brasil. \\ *Autor para correspondência, E-mail: rochellegorczak@gmail.com
}

Resumo. Os répteis (classe Reptilia) animais ectotérmicos com metabolismo bastante lento, possuem anatomia bem diferente dos mamíferos, além disso respondem de forma diferenciada a administração de fármacos. Praticamente não existem espécies dóceis dentro deste grupo de animais, sendo necessária a contenção física ou química para seu manuseio. Existem diferentes métodos de manejo para realizar a contenção física de cada espécie, além da particularidade de cada um com diferentes fármacos anestésicos no momento da contenção química. É muito importante o planejamento de todo procedimento, pois garante segurança para o paciente e equipe. A anestesia desta espécie deve produzir imobilização, analgesia e relaxamento muscular, além de ser seguro e reversível. O objetivo deste trabalho é fazer uma revisão das particularidades anatômicas e fisiológicas de várias espécies de Répteis, assim como dos fármacos anestésicos, visando facilitar a escolha de um protocolo anestésico adequado para cada espécie.

Palavras-chave: Anestesia, insensibilização, silvestres

\section{Chemical and physical restraint of reptiles: Review}

Abstract. The Reptilia class (reptiles) is composed of 8000 species split into four orders: Chelonia (turtles), Crocodilia (crocodilians), Rhynchocephalia (tuatara) and Squamata (lizards and snakes). They are ectothermic animals with sluggish metabolism, lack functional diaphragm, performing the breathing with help of other mechanisms; the response to drugs is differently. There are practically no docile species within this group of animals, requiring physical restraint or chemical restraint. There are different methods to perform the management of physical restraint of each species, each species with a different characteristic to using anesthetics for chemical restraint. In all procedures where the animals are anesthetized have a pre-anesthesia care performed with the use of anesthetic drugs before anesthesia, observation during maintenance of anesthesia, besides monitoring with evaluation of physiological parameters and different reflexes that those animals exhibit during anesthesia.

Keywords: Anesthesia, stunning, wild

\section{Contención química y física de reptiles: Revisión}

Resumen. Los reptiles (clase Reptilia) animales ectotérmicos con metabolismo muy lento, tienen una anatomía muy diferente a la de los mamíferos, además responden de manera diferente a la administración de fármacos. Prácticamente no existen especies dóciles dentro de este grupo de animales, requiriendo contención física o química para su manipulación. Existen diferentes métodos de manejo para realizar la contención física de cada especie, además de la particularidad de cada una con diferentes fármacos anestésicos 
al momento de la contención química. Es muy importante planificar todo el procedimiento, ya que garantiza la seguridad del paciente y del equipo. La anestesia de esta especie debe producir inmovilización, analgesia y relajación muscular, además de ser segura y reversible. El objetivo de este trabajo es revisar las particularidades anatómicas y fisiológicas de varias especies de Reptiles, así como los fármacos anestésicos, con el fin de facilitar la elección de un protocolo anestésico adecuado para cada especie.

Palabras clave: Anestesia, entumecimiento, salvaje

\section{Introdução}

Existem cerca de 13000 répteis no mundo (Branch et al., 2019; Rauber \& Silva, 2020) a maioria dos répteis exigem contenção química para facilitar o exame clínico e procedimentos cirúrgicos (Furtado \& Sobral, 2020). Algumas são perigosas causando mordeduras, aranhões ou envenenamento. Muitas espécies requerem o uso de Equipamento Proteção Individual (EPI) (Freitas et al., 2020).

São animais ectotérmicos e dependem da temperatura ambiente para realização de suas funções metabólicas (Bragagnoli et al., 2020; Pachaly, 2000; Rodrigues et al., 2018). Apresentam metabolismo lento e bastante variância na absorção de fármacos.

A contenção física pode ser realizada de diversas maneiras, dependendo do tamanho e mecanismo de defesa de cada animal (Aguilar \& Hernendéz-Divers, 2006; Rauber \& Silva, 2020). A toalha úmida sobre os olhos, uso de luvas de couro, ganchos, tubos, cordas e fitas são normalmente utilizados (Cubas et al., 2014; Jepson, 2010b). Para realização da contenção química é importante o conhecimento da fisiologia e biologia para o sucesso do procedimento (Frye, 2007).

Este trabalho tem por objetivo fazer uma revisão das particularidades anatômicas e fisiológicas de várias espécies de répteis, técnicas de contenção física e anestesia, visando facilitar a escolha de um protocolo anestésico adequado para cada espécie.

\section{Revisão de literatura}

Existem cerca de 13.000 espécies de répteis (classe Reptilia) divididas em 4 ordens: Chelonia (quelônios), Crocodilia (crocodilianos), Rhynchocephalia (tuataras) e Squamata (serpentes e lagartos) (Branch et al., 2019; Jackson, 2011). Estas quatro ordens estão divididas 60 famílias (Köhler et al., 2006).

Os répteis são animais ectotérmicos, ou seja, são animais incapazes de manter uma temperatura corporal constante por mecanismos fisiológicos intrínsecos. A temperatura influencia diretamente todas as atividades metabólicas do organismo, uma vez que a maior parte das reações bioquímicas é mediada por enzimas e estas por sua vez dependem da temperatura (Castro, 2020; Rodrigues et al., 2018). Todos os répteis têm uma zona de temperatura preferida ótima que é regulada por mecanismos comportamentais e fisiológicos. Os limites de cada zona, particularmente com as espécies de clima temperado, podem variar com as estações do ano (Pachaly, 2000). Fatores ambientais como longos períodos de seca ou temperaturas muito elevadas ou muito baixas influenciam diretamente nos valores hematológicos dos répteis, como a leucocitose (Castro, 2020).

A variação de temperatura ideal fica na faixa de 19 a $34^{\circ} \mathrm{C}$. Acima de $34^{\circ} \mathrm{C}$ eles podem literalmente "cozinhar", pois não conseguem eliminar calor pelo suor. As formas utilizadas para se resfriarem são: a abertura da boca, a evaporação da água pelas mucosas e mergulho na água. Da mesma forma, quando a temperatura fica inferior a $19^{\circ} \mathrm{C}$, começam a entrar em estado letárgico e anoréxico necessitando ficar ao sol para se aquecer. Possuem pele resistente, com escamas, placas ósseas e ossos dérmicos que mantém a umidade do corpo (Oliveira, 2003).

Todos os répteis dependem da temperatura ambiente para suas funções metabólicas (Agguilar \& Hernendéz-Divers, 2006). O metabolismo destes animais tende a ser mais lento do que mamíferos ou aves, assim, e sinais clínicos são mais difíceis de identificar. Processos patológicos normalmente não são observados até que esteja em um estado bem avançado (Luçolli et al., 2017). Por serem animais ectotérmicos sua resposta aos fármacos administrados depende da temperatura ambiente. Por isso é 
indicado manter a temperatura ambiente acima da sua temperatura ótima para alcançar um efeito farmacocinético relevante (Aguilar \& Hernendéz-Divers, 2006; Natalini, 2007; Sawyer, 2008).

Essa classe não possui diafragma funcional, mas um fino septo conjuntivo separando os pulmões das vísceras, mas que em nada influência no movimento da respiração. A respiração se processa por movimentos da faringe para frente e para trás, que desta forma bombeia o ar para os pulmões. Esse processo pode ser em parte auxiliado pelos movimentos da musculatura da cintura peitoral e pélvica, capazes de movimentar as vísceras para cima, comprimindo os pulmões para forçar a saída do ar. Assim sendo, a expiração é ativa e a inspiração é passiva (Hirano, 2011). Entretanto, crocodilianos possuem um sistema respiratório similar ao dos mamíferos, com grande capacidade de armazenamento de ar.

Os quelônios utilizam movimentos de exposição e retração da cabeça, pescoço e os membros a partir do casco, além da musculatura sub lombar, tudo para estimular movimentos respiratórios. No processo de expiração, a contração dos músculos abdominais faz com que as vísceras comprimam a região dorsal do animal, exercendo pressão sob os pulmões. Já na inspiração vai ocorrer o relaxamento e posterior contração dos músculos abdominais, que ao aumentar o volume dada cavidade pleuro peritoneal e faz com que haja expansão dos pulmões, ocorrendo a entrada do ar. Alguns quelônios terrestres têm a capacidade de respirar pela pele e alguns lagartos e serpentes apresentam atrofia ou inexistência de um dos pulmões, geralmente o esquerdo (Stuart, 2017).

No sistema respiratório dos lagartos carnívoros, a glote está localizada cranialmente, enquanto em herbívoros ela é mais caudal, na base da língua, como a maioria dos répteis. Normalmente, a glote fica a maior parte do tempo fechada, pois realizam dois a quatro movimentos respiratórios por minuto, podendo variar com as espécies. Os lagartos e as serpentes possuem traqueia com anéis incompletos e os demais répteis anéis traqueais completos (Aguilar \& Hernendéz-Divers, 2006; Hirano, 2011).

Répteis são animais que se estressam facilmente, por isso não é indicado manipulá-los frequentemente ou sem necessidade (Mader, 1996). Muitas vezes se faz necessária contenção física destes animais (Jepson, 2010b). A técnica para contenção, segundo Fowler (2011) deve ser escolhida levando em consideração quatro fatores: (1) Será seguro para a pessoa que vai conter o animal? (2) Proporciona segurança para o animal em questão? (3) Será possível utilizar o método escolhido durante todo procedimento que querem realizar? (4) Pode ser observado e dado atenção necessária ao animal durante toda imobilização, sendo ela uma contenção química ou física? Se a resposta for positiva, pode ser realizada a imobilização do animal.

As maneiras de contenção física são bastante variadas muitas vezes é utilizada toalha úmida sobre a cabeça para que o animal fique desorientado, uso de luvas de couro entre outros (Cubas et al., 2014; Jepson, 2010b). O tipo de imobilização será determinado a partir do tamanho e dos mecanismos de defesa de cada animal (Aguilar \& Hernendéz-Divers, 2006).

Na contenção de lagartos devem ser observadas as unhas e cauda, pois podem causar ferimentos. Muitos lagartos têm capacidade de soltar a cauda (autotomia) quando se sentem ameaçados ou são manuseados de forma incorreta. Por isso, a cauda nunca deve ser utilizada para a contenção destes animais (Jepson, 2010b; Mayer \& Bays, 2009).

Espécies de tamanho médio e grande devem ser contidos subitamente com uma mão na nuca do animal e outa sobre a cintura pélvica (Cubas et al., 2014). Lagartos pequenos podem ser contidos apenas com a palma da mão e utilizando os dedos para sustentar os membros e a cabeça. Já os venenosos devem ser contidos com auxílio de ganchos ou instrumento similar, pressionando a parte posterior da cabeça, para facilitar imobilização da cabeça e ombros com uma mão e com a outra mão contendo a pélvis (Aguilar \& Hernendéz-Divers, 2006).

Jepson (2010b)cita que muitos lagartos e crocodilianos podem ser imobilizados realizando uma pressão digital sobre as pálpebras fechadas simultaneamente. Está técnica deve ser realizada com manuseio delicado, permitindo que lagartos agressivos sejam avaliados e examinados de forma controlada. Esta manobra faz com que ocorra estimulação vagal e um repouso de curta duração (20-30 segundos), é aplicável em iguanas, monitores e crocodilianos. Deve-se segurar firme a mandíbula e maxila para evitar mordidas e, se possível, amarrar as pernas e cauda para eliminar os movimentos 
(Rubel et al., 2007) além de vendar os olhos dos animais (igura 1) para reduzir o estresse (Hiinarejos et al., 2006b).

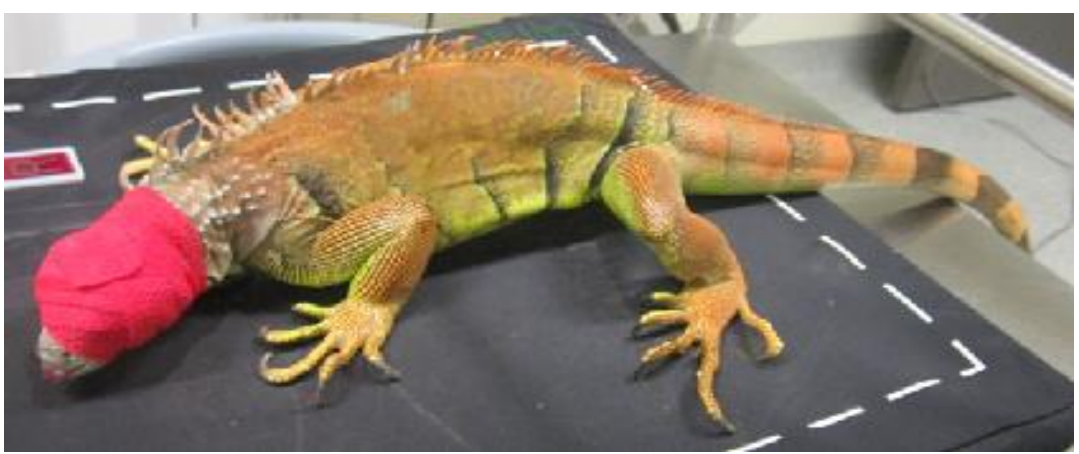

Figura 1. Iguana-verde com os olhos vendados.

As serpentes são os répteis que apresentam a maior variedade de formas de contenção (Oliveira, 2003). A maioria das serpentes, com exceção das peçonhentas e das muito grandes, são de fácil imobilização (Sawyer, 2008). No manejo de serpentes venenosas é preciso utilizar equipamentos especiais e deve ser realizado exclusivamente por um herpetologista ou sob efeito de anestésico (Hiinarejos et al., 2006b; Jepson, 2010c), podendo ser realizado com auxílio do laço de lutz ou de ganchos (Figura 2) (Kolesnikovas et al., 2014).

Os equipamentos desenhados para proteger o manipulador durante o transporte de serpentes venenosas e agressivas, como pinças e ganchos, podem ferir os animais se utilizados inadequadamente. As espécies pesadas devem ser suportadas de modo que seu peso não dependa das suas vértebras cervicais, não sendo seguradas somente pelo pescoço. Os répteis possuem um côndilo occipital, as lesões de luxação atlanto-occipital podem acontecer em contenções inadequadas (타ye, 2007).

Para realizar contenção em superfície plana, é indicado colocar forração de espuma e, quando utilizar o gancho para contenção, a cabeça e o pescoço devem ser empurrados firmemente, de maneira gentil, contra a superfície com espuma (Frye, 2007). Após a captura, a serpente pode ser colocada em uma bolsa ou saco de tela. Deve-se identificar a cabeça e imobilizar antes de abrir a bolsa. Podem ser utilizados escudos de plástico rígidos e ganchos que permitem manejo a distância. $\mathrm{O}$ uso de toalhas é considerado melhor que as luvas de couro, pois possibilita melhora controle da pressão feita sobre o animal (Hiinarejos et al., 2006a) e tubos (Figura 3) onde a serpente é empurrada para dentro e não consegue se mover, este tubo pode ter orifícios que possibilitem a aplicação de injeções e coleta de materiais (Antonio, 2007; Luçolli et al., 2017).

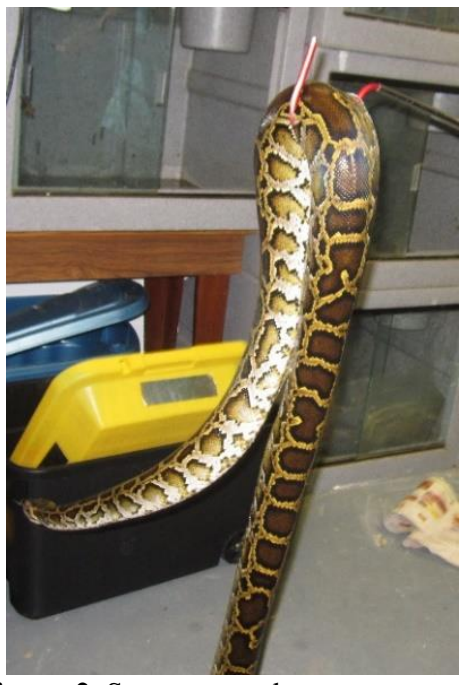

Figura 2. Serpente sendo suspensa com o auxílio de um gancho.

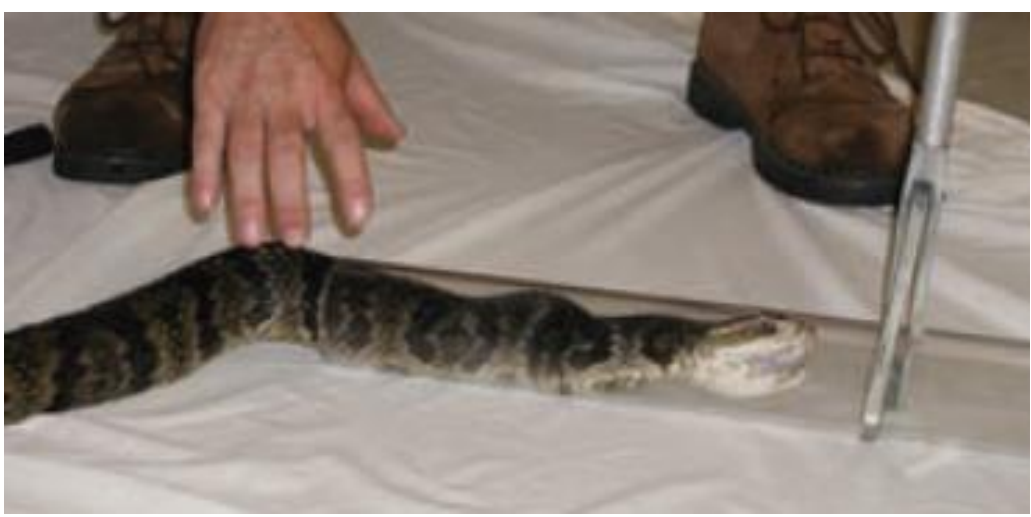

Figura 3. Serpente sendo imobilizada com uso de tubo de contenção. 
A contenção física também pode ser realizada com o laço de Lutz (Figura 4) com bastante segurança para o técnico e o animal. Este permite a realização de pequenos procedimentos, como exame clínico, exame e limpeza da cavidade oral, administração de drogas e punção da veia caudal. Entretanto, caso não seja realizado corretamente o uso do laço pode causar fraturas ou luxações (Kolesnikovas et al., 2014).
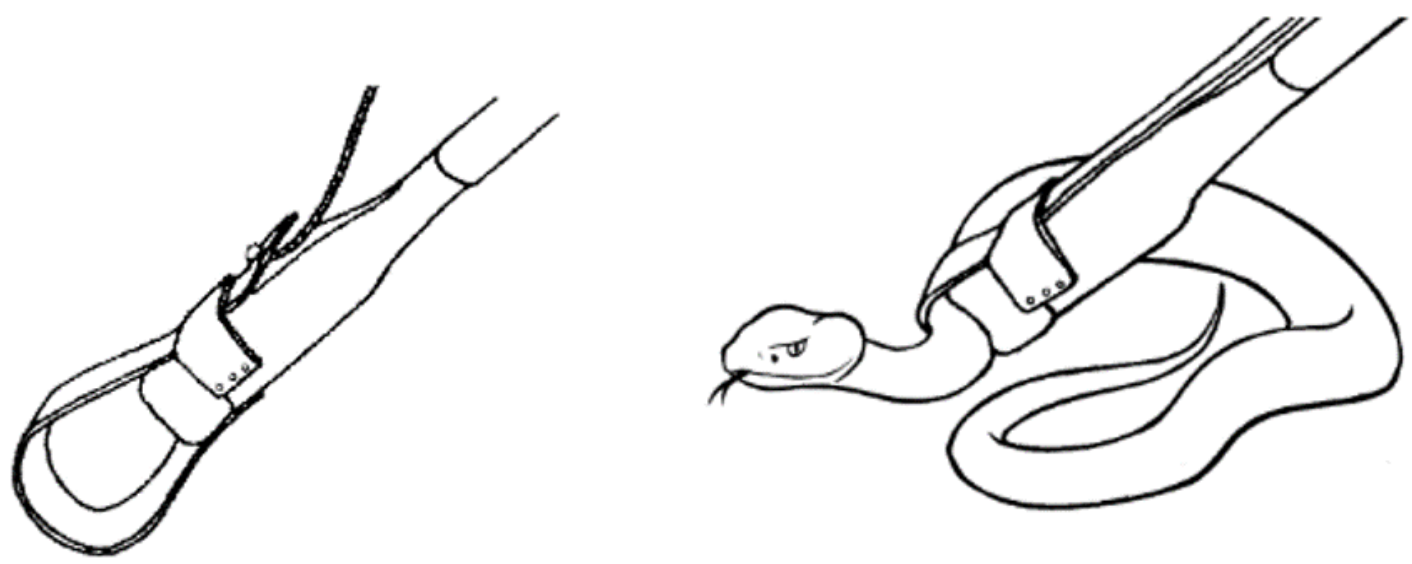

Figura 4. Ilustração do laço de Lutz sendo utilizado em uma serpente. Fonte: Andrade et al. (2002).

A captura de crocodilianos, segundo Bassetti (2007), muitas vezes é realizada em função do recinto ou ambiente que o animal se encontra. Pode ser realizada drenagem completa de tanques pequenos, para capturar animais de até 1 metro. Nestes animais os métodos de contenção física, com atadura fechando a boca (figura 5) são preferidos aos de contenção química (Lance, 2013).

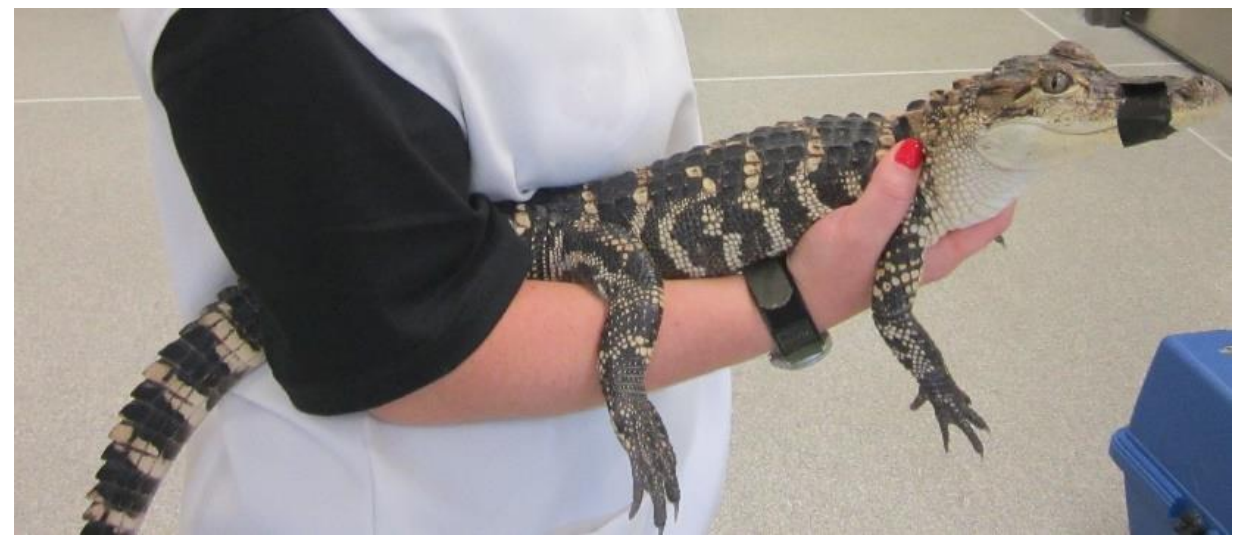

Figura 5. Jacaré-americano (Alligator mississippiensis) jovemimobilizado com auxílio do braço.

Como crocodilos maiores são animais muito perigosos a técnica envolve passar um laço na cabeça e enrolar um cabo sobre a pelve, amarrando os membros firmemente (Figura 6) para evitar que o animal se vire. Feito isso deve ser colocado um pano, que pode ser úmido, sobre os olhos do animal, fazendo com que se acalme e não possa fixar um alvo. Se deve amarrar e fechar firmemente a boca (Figura 7), sempre com auxílio de mais de uma pessoa (Lance, 2013). É indicado sentar sobre o animal fazendo pressão manual no nariz, mantendo o animal imobilizado e o peso do imobilizador não pode impedir o animal de respirar (Bassetti, 2007; Rauber \& Silva, 2020).

$\mathrm{Na}$ contenção de quelônios terrestres há muita preocupação com mordeduras. É necessário cuidados com grandes cágados ou espécies perigosas como a tartaruga mordedora, que devem ser contidas pela porção posterior da carapaça ou pela base da cauda (Jepson, 2010a). Apresentam forte musculatura nos membros e pescoço, por isso se deve ter cuidado para não deixar os dedos presos entre membro locomotor e carapaça (Cubas et al., 2014). Materiais como fita adesiva ou tubos de diversos diâmetros podem ser utilizados para contenção assim evitando mordidas (Furtado \& Sobral, 2020). O animal pode ser contido apenas utilizando um pequeno pote plástico apoiado sobre o plastrão 
(Figura 8) e se for preciso evitar movimento dos membros é só passar uma fita ou faixa sobre a carapaça envolvendo os membros (Figura 9) (Goulart, 2004).

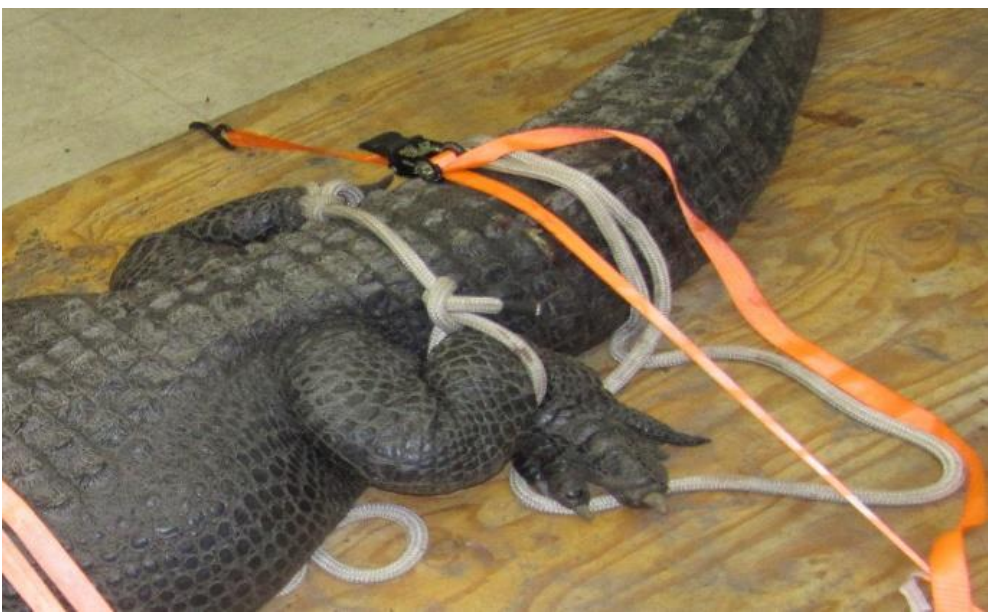

Figura 6. Jacaré-americano (Alligator mississippiensis) com os membros posteriores amarrados.

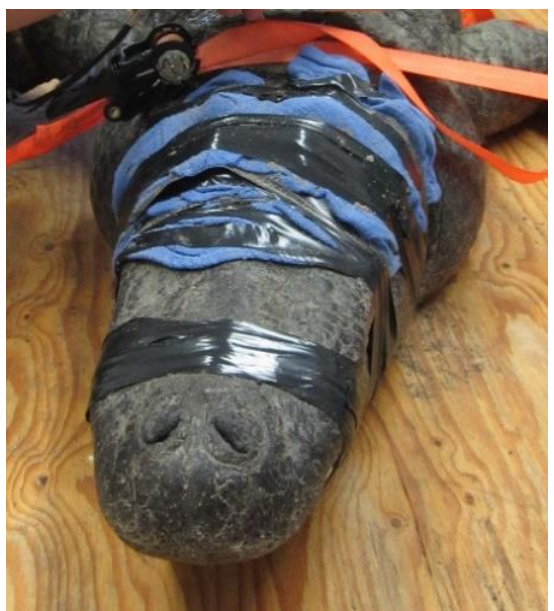

Figura 7. Jacaré-americano (A. mississippiensis) jovemimobilizado com auxílio do braço.

Esses animais não são difíceis de manipular, mas podem dificultar o exame com sua força e natureza não cooperativa. Uma técnica utilizada é sustentar o animal com cabeça para baixo, depois de um tempo ele colocará a cabeça para fora da carapaça, assim coloca-se o polegar e dedo médio atrás do côndilo do occipital, prevenindo a retração da cabeça em espécies menores (Hernández-Divers \& Hernández-Divers, 2006; Schumacher, 2007).

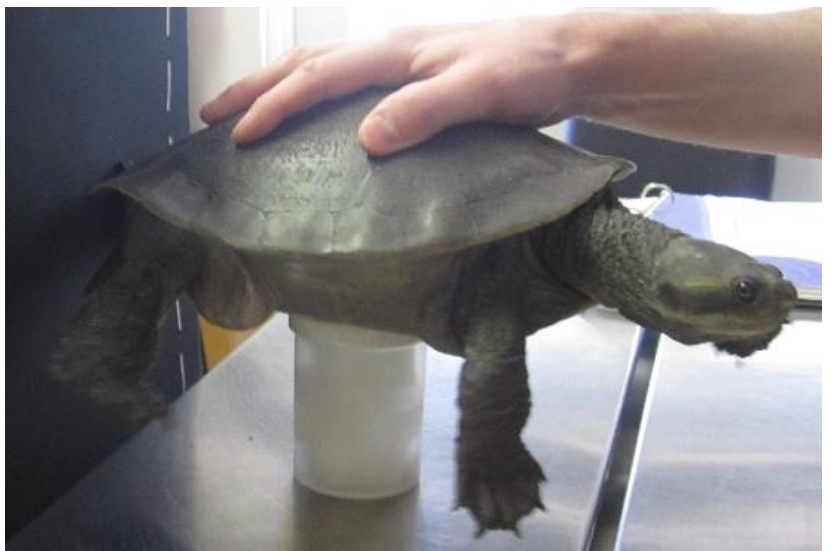

Figura 8. Quelônio contido apoiado em um pequeno pote plástico.

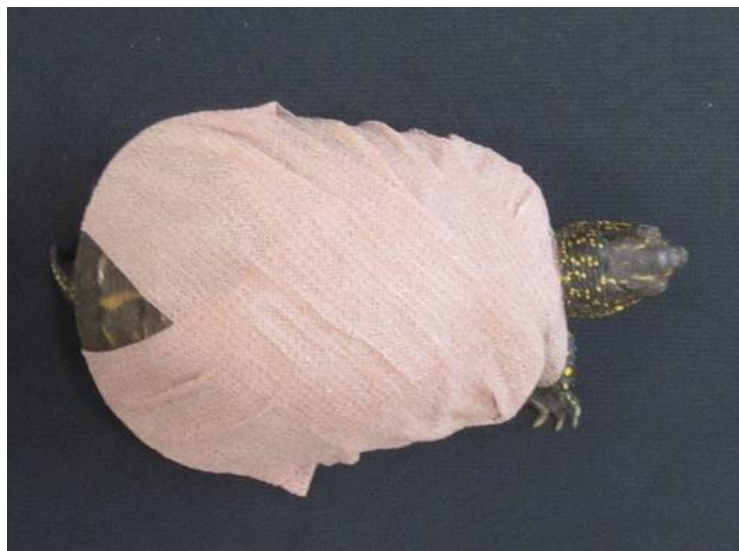

Figura 9. Quelônio contido com uso de faixa.

A contenção química ou anestesia de répteis deve levar em conta o conhecimento da fisiologia e biologia dos mesmos, pois, por serem ectotérmicos reagirão de forma imprevisível aos fármacos em condições ambientais diferentes (Frye, 2007). Além disso, é necessário o conhecimento e compreensão sobre a fisiopatologia das doenças comuns nestes animais antes de selecionar um protocolo anestésico (Sawyer, 2008). Lembrando dos parâmetros básicos como frequência respiratória normal para diversos répteis se mantém entre 10 e 20 movimentos respiratórios por minuto, ao utilizar oxigênio a 100\%, esta frequência pode reduzir para 2 a 4 movimentos (Luçolli et al., 2017).

Segundo Sawyer (2008) os padrões e princípios para realizar a anestesia nestes animais deve, sempre que possível, ser os mesmos utilizados no trabalho com pequenos animais, observando o histórico completo, realização de exame visual, físico e verificação do peso corporal. Antes de um paciente ser levado para procedimento anestésico é de extrema importância a avaliação do estado geral, nutricional, hidratação, presença de infecções e principalmente, o estado metabólico para poder determinar o risco cirúrgico. Sendo que pacientes em más condições, desidratados e em período de hibernação, apresentam risco máximo anestésico, e não devem ser submetidos a nenhuma intervenção até que se restabeleçam. Em caso de cirurgia não eletiva iniciar estabilização 24 horas antes do 
procedimento. Animais operados durante a saída da hibernação apresentam menor risco do que aqueles que estão entrando. Além disso, em algumas ocasiões, o período de hibernação pode ser alterado, modificando a temperatura ambiente, para que o animal tenha uma taxa metabólica mais elevada no período pós-operatório (Píparo, 2007).

Em geral, quando é preciso realizar fluidoterapia, deve ser na temperatura corporal preferível de cada espécie (normalmente entre $25^{\circ} \mathrm{C}$ e $35^{\circ} \mathrm{C}$ ) e pode ser administrada por diferentes vias, como oral (VO), intracelômica (ICE), intravenosa (IV) ou intracardíaca (IC) esta última mais comum em ofídios (Hiinarejos et al., 2006a).

Em quelônios e lagartos é indicado um jejum pré-anestésico de 24-72 horas, isso para evitar a pressão dos pulmões e a regurgitação (Hernández-Divers \& Hernández-Divers, 2006; Hiinarejos et al., 2006b). No caso de serpentes é aconselhado jejum de 24-96 horas para evitar a putrefação da comida ingerida. Em espécies maiores, como píton e jiboia, este jejum deve ser de 7 a 14 dias (Hiinarejos et al., 2006a).

O protocolo anestésico deve produzir imobilização, analgesia e relaxamento muscular para ter boa anestesia, além de ser seguro e facilmente reversível. A via de aplicação dos medicamentos e a temperatura corporal do animal são fatores importantes na ação das drogas anestésicas (Cubas et al., 2014). E ainda compreender que a evolução em répteis submetidos a anestesia do relaxamento muscular acontece no sentido crânio-caudal. E na recuperação, a função motora retorna em sentido inverso (Santos et al., 2012).

A via subcutânea é raramente utilizada em répteis, devido à lenta captação farmacológica. Enquanto as vias intraósseas e IV são de mais rápida ação de fármacos e são favoráveis para aplicação de medicamentos de emergência ou anestesia. Normalmente a via IM é a de eleição, devido a farmacocinética ser mais uniforme e confiável (Hernández-Divers \& Hernández-Divers, 2006; Maia et al., 2009; Schumacher, 2007). Quando utilizamos medicamentos pela via IM, devemos evitar os membros posteriores, pois os répteis são animais metanéfricos e possuem um sistema porta renal que normalmente drena a metade posterior do corpo direto para os rins antes de passar pela circulação geral e retornar ao coração (Kolesnikovas et al., 2014).

A hipotermia reduz os movimentos do animal. Entretanto, é uma técnica inaceitável como técnica anestésica, considerando o bem-estar animal, além de afetar a farmacocinética de qualquer agente administrado e prolongar muito a recuperação do paciente (Hernández-Divers \& Hernández-Divers, 2006; Natalini, 2007).

A medicação pré-anestésica (MPA) é o ato que antecede a anestesia, e se caracteriza pela sedação do animal, tendo a finalidade de tranquilizar, diminuindo a irritabilidade, a agressividade e a dose dos anestésicos gerais. Estes medicamentos têm a característica de serem analgésicos e hipnoanalgésicos, o que facilita o manejo do animal (Universidade de Évora, 2011).

A atropina pode ser utilizada associada na MPA na dose de $0,044 \mathrm{mg} / \mathrm{kg}, \mathrm{IV}, \mathrm{SC}$ ou IM, reduzindo a secreção mucosa no trato respiratório com uma ação broncodilatadora, sem causas alterações significativas no SNC (Bolfer et al., 2004). Entretanto, segundo Carpenter (2007), esse fármaco só deverá ser utilizado em caso de bradicardia.

Os tranquilizantes mais usados são os fenotiazínicos e benzodiazepínicos. A acepromazina, é um fenotiazínico, pode ser utilizada na dose de 0,1 a $0,5 \mathrm{mg} / \mathrm{kg}$, IM, uma hora antes da indução anestésica. Ela suaviza a indução e diminui a quantidade de outros agentes durante o procedimento. Os benzodiazepínicos como o diazepam $(0,22$ a $0,62 \mathrm{mg} / \mathrm{kg})$ e o midazolam $(2 \mathrm{mg} / \mathrm{kg})$ podem ser administrados 20 minutos antes da indução anestésica. Podem ser utilizados associados à quetamina ou tiletamina com zolazepam para potencializar a anestesia (Cubas et al., 2014; Pachaly, 2000). Os benzodiazepínicos apresentam vantagens como produzir pouca depressão cardiopulmonar, pode ser utilizado em pacientes debilitados e proporcionam um bom relaxamento muscular. Entretanto, o diazepam quando administrado pela via IM é doloroso e se administrado pela via IV deve ser lento, pois pode causar hipotensão, bradicardia e apneia (Goulart, 2004).

Não é recomendado o uso de xilazina (sedativo alfa-2 agonista), pois nestes animais apresenta grande variação. Doses de 0,1 até $1,25 \mathrm{mg} / \mathrm{kg}$ podem produzir desde moderada alteração de 
consciência a profunda sedação, mesmo em indivíduos semelhantes. A latência deste fármaco pode demorar de 10 minutos a mais de uma hora e a recuperação anestésica pode variar de menos de uma hora até mais de 12 horas (Cubas et al., 2014; Pachaly, 2000).

Analgésicos devem ser utilizados em procedimentos (Tabela 1) em que o paciente possa apresentar dor. Os opioides agem modulando a nocicepção na periferia, medula e em áreas supraespinhais do SNC. No entanto, devido aos répteis possuírem um SNC primitivo, a ação antinociceptiva central desses fármacos precisa ser mais estudada (Maia et al., 2009). Assim como a morfina, o butorfanol pode apresentar efeitos controversos nestes pacientes, pesquisas afirmam que este fármaco agonista kappa-antagonista mu pode ser utilizado em doses variadas SID ou BID, dependendo do procedimento que o animal foi submetido, porém para serpentes a resposta analgésica se faz com uso de doses mais elevadas (Bressan, 2017). A morfina também pode ser uma escolha, pois age nos receptores $\mu$, que são predominantes nesta espécie. Pode fornecer antinocicepção por até 24 horas dependendo da espécie (Maia et al., 2009). Outro opioide é o fentanil, que possui ação ultracurta, por isso é recomendado administração IV com ação imediata e com duração de 30 minutos. Nos répteis é utilizado na dose de $0,0025 \mathrm{mg} / \mathrm{kg}$ (Cubas et al., 2014; Pachaly, 2000).

Tabela 1. Agentes analgésicos utilizados em répteis. Modificado de Carpenter (2007)

\begin{tabular}{llll}
\hline Agente & Dose/Via & Espécie & Comentário \\
\hline Bupivacaina & $1-2 \mathrm{mg} / \mathrm{kg}$ local & Maioria & Dose máxima 4 mg/kg BID ou TID prn \\
\hline \multirow{3}{*}{ Butorfanol } & $0,4-1 \mathrm{mg} / \mathrm{kg} \mathrm{SC}$, IM & Maioria & Analgesia, sedação, MPA \\
& $1-2 \mathrm{mg} / \mathrm{kg} \mathrm{IM}$ & Serpentes & Analgesia \\
& $20 \mathrm{mg} / \mathrm{kg} \mathrm{IM}$ & Serpentes & Potente analgesia \\
\hline Carproflan & $2 \mathrm{mg} / \mathrm{kg} \mathrm{SC}$, IM & Maioria & AINE, analgesia, SID \\
Flunixin meglumine & $0,1-2 \mathrm{mg} / \mathrm{kg}$ IM & Maioria & AINE, analgesia, SID ou BID, máximo 3 dias \\
& $1-2 \mathrm{mg} / \mathrm{kg}$ IM & Lagartos & AINE, analgesia pós-cirúrgica, BID x 2 dias \\
\hline \multirow{2}{*}{ Lidocaína } & $2-5 \mathrm{mg} / \mathrm{kg} \mathrm{Local}$ & Maioria & Dose máxima de 10 mg/kg \\
\hline \multirow{3}{*}{ Meloxican } & Local ou tópico & Maioria & q24- 48h \\
& $0,1-0,5 \mathrm{mg} / \mathrm{kg}$ VO, SC & Maioria & SID \\
\hline \multirow{2}{*}{ Morfina } & $0,2 \mathrm{mg} / \mathrm{kg} \mathrm{VO}, \mathrm{IV}$ & Iguanas & SID x 4-10 dias \\
& $0,1-0,2 \mathrm{mg} / \mathrm{kg}$ VO, IM & Quelônios & \\
\hline Predinisona & $1,5-6,5 \mathrm{mg} / \mathrm{kg} \mathrm{IM}$ & Maioria & Pode causar depressão respiratória \\
\hline \multirow{2}{*}{ Tramadol } & $10 \mathrm{mg} / \mathrm{kg} \mathrm{IM}$ & Lagartos e dragão-barbudo & \\
\hline & $0,5-4 \mathrm{mg} / \mathrm{kg}$ Ice & Crocodilianos & Dor crônica \\
\hline
\end{tabular}

Indução anestésica é a transição do paciente do estado consciente para o inconsciente. Esta é a parte mais perigosa durante uma anestesia, pois sistemas do corpo passam para um estado instável, onde indesejáveis respostas cardiovasculares e respiratórias podem acabar sendo observadas (Sawyer, 2008).

Existem diferentes protocolos atribuídos aos répteis, porém o agente de indução anestésica de eleição é o propofol, na dose de $14 \mathrm{mg} / \mathrm{kg}$ para quelônios e entre $5-10 \mathrm{mg} / \mathrm{kg}$ para as demais espécies de répteis. Pode ser empregado pelas vias IV ou IC, nesta última, em uma única aplicação em serpentes. Este fármaco é relativamente atóxico e com risco baixo de causar tromboflebite em uma administração perivascular. É preciso ter atenção especial no ato da indução anestésica, pois pode ocorrer apneia transitória, que normalmente retorna ao normal com um pequeno estimulo ou após um breve período de manutenção artificial da respiração. Pode ser utilizado sozinho ou associado a um dissociativo como a tiletamina/zolazepam na dose de $5 \mathrm{mg} / \mathrm{kg}$, IM (Hiinarejos et al., 2006b).

Os anestésicos dissociativos, como a quetamina e tiletamina com zolazepam são comumente empregados em répteis, apresentando vantagem como margem de segurança e uniformidade do comportamento anestésico (Ishiy et al., 2002). O anestésico injetável mais utilizado em répteis é a 
quetamina, nas doses entre 22 e $44 \mathrm{mg} / \mathrm{kg}$ para sedação e de 55 a $88 \mathrm{mg} / \mathrm{kg}$ para anestesia. Para algumas serpentes a dose é entre 90 e $154 \mathrm{mg} / \mathrm{kg}$, podendo chegar a dose de $220 \mathrm{mg} / \mathrm{kg}$ para atingir plano anestésico cirúrgico, com indução de normalmente 10 a 30 minutos e recuperação variando de 2 a 72 horas conforme a dose e temperatura (Pachaly, 2000). Esse dissociativo pode ser utilizado isoladamente ou em associação com o diazepam (Cubas et al., 2014). Além disso, a associação de quetamina, medetomidina e butorfanol proporcionam um ótimo relaxamento reversível em muitas espécies (Hernández-Divers \& Hernández-Divers, 2006; Schumacher, 2007). A anestesia realizada com tiletamina e zolazepam é mais potente que o uso da quetamina isolado (Cubas et al., 2014; Pachaly, 2000). Uma grande desvantagem do uso de dissociativos é o tempo que levam no retorno anestésico, podendo ser de 24 a 72 horas, enquanto no uso de propofol é de 30 a 45 minutos (Hiinarejos et al., 2006a). Outro fármaco utilizado na indução anestésica é o etomidato, uma droga que exerce os mínimos efeitos cardiovasculares e respiratórios, apresentando rápida distribuição e com curta duração de efeitos, em torno de 10 minutos. As doses deste fármaco podem variar conforme a espécie (Pachaly, 2000).

Em cirurgias, de amputação de pênis ou em procedimentos nos membros posteriores, é indicado o uso de anestesia epidural, realizada com lidocaína $2 \%$ com vasoconstritor. Para anestesia na cauda e região pericloacal a dose estimada é de $0,1 \mathrm{~mL}$ para cada $5 \mathrm{~cm}$ do comprimento da carapaça. Utilizando o dobro da dose, permite-se a anestesia também nos membros posteriores. A aplicação é feita no espaço intervertebral no dorso da cauda, entre o terço médio e distal (Cubas et al., 2014).

A intubação de répteis é simples. A sonda ou cateter endotraqueal de pequeno calibre é inserido facilmente através da glote, imediatamente caudal a língua, o que pode ser facilitado forçando a língua para cima e para frente e fazendo uma pressão com um dedo dentro do espaço intermandibular debaixo da mandíbula. Também é possível utilizar um mandril como guia para facilitar a colocação da sonda endotraqueal (Hernández-Divers \& Hernández-Divers, 2006). Segundo Hiinarejos et al. (2006b) a sonda endotraqueal deve ser curta, pois os lagartos e a maioria dos quelônios apresentam a bifurcação da traqueia bem cranial. Além disso, os crocodilianos e a maioria dos quelônios apresentam anéis traqueais completos por isso a sonda não deve ter balão de cuff (igigura 10) e, se tiver, esse não deve ser inflado (Hirano, 2011).

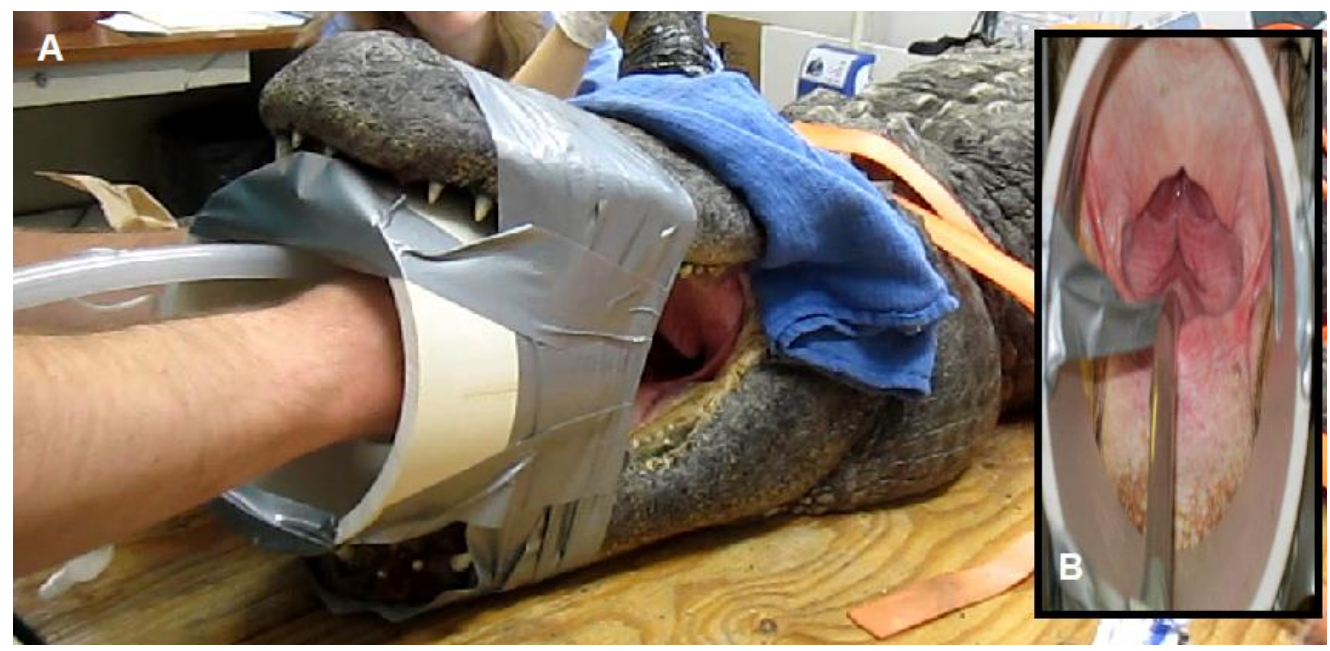

Figura 10. A- Jacaré-americano (Alligator mississippiensis) sendo intubado e B- Vista da glote com o animal intubado.

Após indução, é indicado realizar a manutenção com anestesia inalatória, pois possibilita melhor controle da depressão anestésica e recuperação mais rápida (Natalini, 2007). O isoflurano ou sevoflurano são os agentes anestésicos mais indicados e o fluxo de oxigênio em animais pequenos deve ser um litro animais até $1 \mathrm{~kg}$ e em répteis maiores um litro para cada 5 ou $10 \mathrm{~kg}$. Na manutenção anestésica com agente inalatório deve ser utilizada uma concentração de 1-3\% se o agente inalatório for isoflurano ou porcentagens mais altas se for utilizado sevoflurano (Hiinarejos et al., 2006a, 2006b). Entretanto, Cubas et al. (2014) recomendam concentração de 1,5-2,5\% de isoflurano e quando 
utilizado para indução na concentração de 5\%, todavia segundo (Hiinarejos et al., 2006a) a indução direta com anestésico inalatório aumenta o risco de apneia.

É recomendado, durante a manutenção anestésica, o uso de respiração assistida, seja manual ou com um ventilador artificial, a cada 15-30 segundos (Hiinarejos et al., 2006a). Em quelônios é indicada cautela quando utilizar o ventilador, para não superinflar ou lesionar os pulmões. O melhor é o uso de ventilador automático que permite o controle da pressão de ventilação e a frequência necessária. Ao final de um procedimento é importante fechar o vaporizador e manter o animal na ventilação por pelo menos mais cinco minutos, apenas no oxigênio, para facilitar a eliminação do agente anestésico (Hernández-Divers \& Hernández-Divers, 2006).

Parte muito importante da anestesia é o monitoramento, onde são utilizados todos os métodos aplicados aos mamíferos no transoperatório. O monitoramento cardiorrespiratório é importante, pois permanecem em apneia por vários minutos. O que é observado, especialmente nos quelônios, nos quais não podemos notar o movimento respiratório e nos lagartos, que, diante de um grande estresse, podem passar para um metabolismo anaeróbico, dificultando a verificação da ventilação. É muito difícil auscultar os batimentos cardíacos de répteis utilizando estetoscópio, por isso é preciso usar estetoscópio esofágico e equipamentos eletrônicos de amplificação, como o Doppler, que pode ser colocado sobre o coração ou garganta, para observar o fluxo sanguíneo através de sinais sonoros e uso de eletrocardiograma são ferramentas fundamentais para o acompanhamento do paciente (Flôres, 2008). Também é indicado utilizar o oxímetro de pulso, na cloaca ou língua, para avaliar a saturação de oxigênio pela na hemoglobina do sangue arterial (Natalini, 2007; Píparo, 2007).

Durante a indução anestésica, o animal perde o reflexo de endireitamento, o qual é avaliado colocando o animal em decúbito dorsal e ele retorna ao decúbito esternal (Figura 11). Este reflexo é um bom indicador na recuperação anestésica. A perda do tônus mandibular e o reflexo de dor nas extremidades e na cauda normalmente indicam plano anestésico adequado. Durante o plano cirúrgico, o reflexo corneal se mantém, e a ausência deste significa que o animal está em plano profundo (Hiinarejos et al., 2006b). Este reflexo é testado tocando suavemente a córnea e verificando a existência do reflexo de piscar a pálpebra devido à estimulação tátil. Este reflexo é suprimido em doses tóxicas e o diâmetro pupilar possui pouca relação com a profundidade anestésica (HernándezDivers \& Hernández-Divers, 2006).

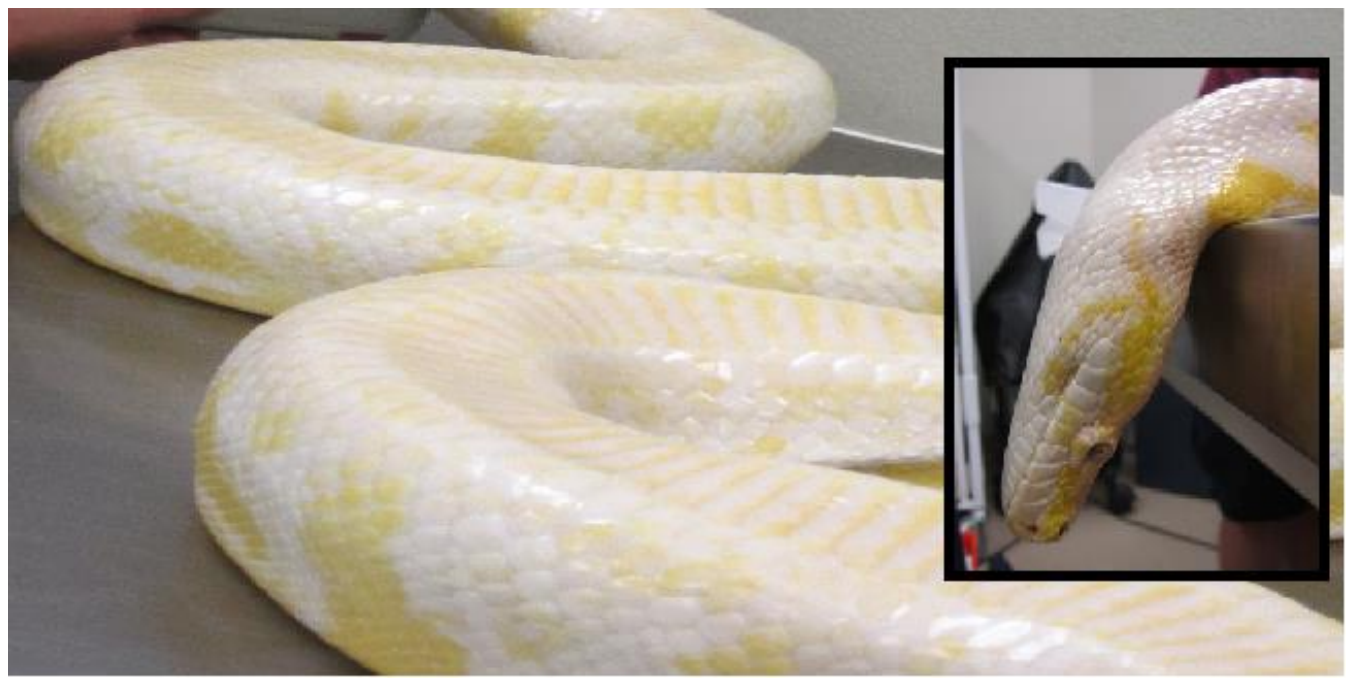

Figura 11. Serpente anestesiada não respondendo ao reflexo de endireitamento.

Para monitoramento anestésico de serpentes não se avalia reflexo palpebral, pois as mesmas não possuem pálpebras. A parte da pálpebra inferior é fundida com a superior, através de uma camada transparente que cobre todo o olho, conhecido como "escudo" de proteção nos olhos (Burnie, 2008). Como a abolição dos sentidos e reflexos se processa em um sentido craniocaudal, a sensibilidade da cauda é a última a ser abolida. Um fato bem evidente em serpentes, é que possuem sensibilidade e coordenação motora muito acentuada na cauda. Nestes animais deve-se testar com uma agulha na 
ponta da cauda: se a cauda não reagir, indicará plano anestésico profundo, entretanto se apresentar movimentos involuntários de cauda, o animal estará em plano anestésico superficial (Goulart, 2004).

Em todos os casos cirúrgicos, almofadas térmicas, bolsas de água quente ou qualquer outra fonte de calor deve ser colocada entre o paciente e a mesa, a fim de manter elevado o seu metabolismo. Este procedimento além de facilitar a eliminação das drogas e ter um paciente pós-cirúrgico de menor risco, também acelera sua recuperação. Um jeito simples de aumentar a temperatura da superfície da mesa metálica é a colocação de uma lâmpada infravermelha logo abaixo da mesa, virada em sua direção. Neste caso é importante realizar a verificação da temperatura da mesa que deve estar entre $35^{\circ} \mathrm{C}$ e $38^{\circ} \mathrm{C}$ (Píparo, 2007). Entretanto, conforme Oliveira (2003), a indução, manutenção e recuperação devem ser realizadas dentro da variação de temperatura de $26^{\circ} \mathrm{C}$ a $32^{\circ} \mathrm{C}$ e Goulart (2004) ainda explica que se a temperatura for mantida inferior a ideal da espécie o tempo de indução e retorno do agente anestésico se tornam maiores. Após um procedimento anestésico todos os répteis deveriam ficar internados e mantidos com temperatura ideal durante todo o tempo, para minimizar os distúrbios fisiológicos, facilitar a recuperação e a imunocompetência (Hernández-Divers \& Hernández-Divers, 2006).

No controle da dor pós-operatória ou crônica em répteis é utilizado anti-inflamatórios não esteroidais, como o cetoprofeno, carprofeno e meloxican. Entretanto ainda são escassas pesquisas sobre seus efeitos secundários como irritação trato gastrintestinais, lesão renal e alteração da coagulação.

\section{Conclusão}

Foi possível constatar que as técnicas de contenção dos animais silvestres são bem diferenciadas das empregadas nos animais domésticos, bem como a importância do treinamento e estudo das pessoas que trabalham com esses animais e completa interação da equipe para assegurar a segurança de todos, inclusive dos animais. São animais com um metabolismo bastante diferenciado e com diversas particularidades para anestesia. $\mathrm{O}$ estudo dos diferentes fármacos acaba se torando muito importante para contenção das diferentes espécies, além das diferentes técnicas que podem ser utilizadas no momento da contenção física. Répteis possuem morfofisiologia diferente das demais classes e estão rapidamente se tornando populares fazendo com que aumente o número de pacientes para clínicos veterinários de animais silvestres.

\section{Referências}

Aguilar, R., \& Hernendéz-Divers, S. M. (2006). Atlas de Medicina, Terapêutica e Patologia de Animais Exóticos. Interbook.

Andrade, A., Pinto, S.C. \& Oliveira, R.S. (2002). Animais de Laboratório: criação e experimentação [online]. Rio de Janeiro: Editora FIOCRUZ. p.388.

Antonio, F. B. (2007). Venomus reptile restreint and handling. In G. West, D. Heard, \& N. Caukett (Eds.), Zoo Animal and Wildlife Immobilization and Anesthesia. Blackwell Publishers Inc.

Bassetti, L. A. B. (2007). Crocodylia (Jacaré, Crocodilo). In Z. S. Cubas, J. C. R. Silva, \& J. L. CatãoDias (Eds.), Tratado de Animais Selvagens. Roca Ltda.

Bolfer, L. H. G., Silva, E. C. M., Lanza, C. M. E. S., Meyer, M., Fanuchi, L., Sotello, A., \& Teixeira, R. B. (2004). Medicação pré-anestésica - Revisão de literatura. Anais Da Semana Acadêmica de Medicina Veterinária, 12-15.

Bragagnoli, A. L., Souza, J. G., Soares, K. L., Pereira, S., Carreiro, A. N., Henrique, F. V, \& Nóbrega Neto, P. I. (2020). Efeitos do propofol administrado por via intracelomática em cágados-debarbicha (Phrynops geoffroanus) Schweigger, 1812. Arquivo Brasileiro de Medicina Veterinária e Zootecnia, 72(2), 405-410. DOI: https://doi.org/10.1590/1678-4162-11039

Branch, W. R., Pinto, P. V., Baptista, N., \& Conradie, W. (2019). Os répteis de Angola: história, diversidade, endemismo e hotspots. In B. J. Ntley, V. Russo, \& N. F. Almeida (Eds.), Biodiversidade de Angola. Portugal.Branch. 
Bressan, T. F. (2017). Localização dos receptores opioides no sistema nervoso central e avaliação dos efeitos analgésico e sedativo da morfina e butorfanol em iguanas verdes (Iguana iguana). Universidade de São Paulo.

Burnie, D. (2008). Illustrated encyclopedia of animals. Dorling Kindersey.

Carpenter, J. W. (2007). Exotic animal formulary. 3.ed.St. Sauders: Elsevier, Louis, Missouri, USA. Saunders Elsevier.

Castro, G. S. (2020). Influência da sazonalidade e do sexo na hematologia, na citoquímica e na bioquímica do estresse oxidativo e metabólico de Chelonoidis carbonarius (Spix, 1824), mantidos em cativeiro. Universidade Estadual Paulista (UNESP).

Cubas, Z. S., Silva, J. C. R., \& Dias, J. L. C. (2014). Tratado de animais selvagens-medicina veterinária. Editora Roca.

Flôres, F. N. (2008). Anestesia em tartaruga para remoção cirúrgica de granuloma - relato de caso. Revista Da Faculdade de Zootecnia, Veterinária e Agronomia, 15(1), 132-140.

Fowler, M. (2011). Restraint and handling of wild and domestic animals. John Wiley \& Sons.

Freitas, D. C., Gomes, W. P. B. S., Silva, R. C. C., \& Seibert, C. S. (2020). Serpentes: é possível conviver com elas? Revista Brasileira de Ecoturismo, 13(3), 572-586. DOI: https://doi.org/10.34024/rbecotur.2020.v13.9354

Frye, F. L. (2007). Condições patológicas relacionadas ao ambiente de cativeiro. Anais III Jornada Grupo Fowler: Encontro Nacional de Medicina de Répteis, 13-42.

Furtado, G. D., \& Sobral, F. E. S. (2020). Contenção mecânica de animais: revisão bibliográfica. Enviromental Smoke, 3(3), 38-47. DOI: https://doi.org/10.32435/envsmoke.20203338-47

Goulart, C. E. S. (2004). Herpetologia, herpetocultura e medicina de répteis (1 Ed., Vol. 1). LF Livros.

Hernández-Divers, S. M., \& Hernández-Divers, S. J. (2006). Quelônios. In R. Aguilar, S. M. Hernández-Divers, \& S. M. Hernández-Divers (Eds.), Atlas de medicina, terapêutica e patologia de animais exóticos. Interbook.

Hiinarejos, D. P., Hernández-Divers, S. M., \& Hernández-Divers, S. J. (2006a). Ofídios. In R. Aguilar, S. M. Hernández-Divers, \& S. M. Hernández-Divers (Eds.), Atlas de Medicina, Terapêutica e Patologia de Animais Exóticos. Interbook.

Hiinarejos, D. P., Hernández-Divers, S. M., \& Hernández-Divers, S. J. (2006b). Saurios. In R. Aguilar, S. M. Hernández-Divers, \& S. M. Hernández-Divers (Eds.), Atlas de Medicina, Terapêutica e Patologia de Animais Exóticos. Interbook.

Hirano, L. Q. L. (2011). Contenção farmacológica de jacaré-tinga Caiman crocodilus Linnaeus, 1758 com cetamina $S(+)$ e cetamina racêmica, isolada ou em associação com o midazolam. Universidade Federal de Uberlândia.

Ishiy, H. M., Luna, S. P. L., Gonçalves, R. C., \& Cruz, M. L. (2002). Uso da lidocaína isolada ou associada à quetamina ou ao butorfanol, em anestesia epidural em cadelas submetidas à ovariosalpingohisterectomia. Revista Brasileira de Ciência Veterinária, 9(1), 134-136.

Jackson, T. (2011). Animals visual encyclopedia. Amber.

Jepson, L. (2010a). Jabutis e cágados. In L. Jepson (Ed.), Clínica de Animais Exóticos: referência rápida. Sauders Elsevier.

Jepson, L. (2010b). Lagartos. In L. Jepson (Ed.), Clínica de Animais Exóticos: referência rápida. Sauders Elsevier.

Jepson, L. (2010c). Serpentes. In L. Jepson (Ed.), Clínica de Animais Exóticos: referência rápida. Sauders Elsevier.

Köhler, G., Veselý, M., \& Greenbaum, E. (2006). The amphibians and reptiles of El Salvador. Krieger Publishing Company.

Kolesnikovas, C. K. M., Grego, K. F., \& Albuquerque, L. C. R. (2014). Squamata (Serpentes). In Z. S. Cubas, J. C. R. Silva, \& J. L. Catão-Dias (Eds.), Tratado de Animais Selvagens. Roca Ltda.

Lance, W. R. (2013). Chemical and physical restraint of wild animals, a training and field manual for 
African species. Journal of Wildlife Diseases, 49(1), 214. DOI: https://doi.org/10.7589/0090-355849.1.214

Luçolli, D. B., Hertel, L. B., Inaba, C. H. G., \& Motta, D. (2017). Anestesia em Bothrops oojeni para exame radiográfico da cavidade oral - relato de caso. Revista Eletrônica de Biociências, Biotecnologia e Saúde, 10(19), 47-49.

Mader, D. R. (1996). Reptile Medicine and Surgery-E-Book. Elsevier Health Sciences.

Maia, J. Z., Rodrigues, P. R. C., Pulz, R. S., \& Pinto, V. M. (2009). Anestesia em animais silvestres. Ulbra.

Mayer, J., \& Bays, T. B. (2009). Comportamento de répteis. In T. B. Bays, T. Lightfoot, \& J. Mayer (Eds.), Comportamento de animais exóticos de companhia: aves, répteis e mamíferos de pequeno porte. Roca, Brasil.

Natalini, C. C. (2007). Teoria e técnicas em anestesiologia veterinária. Srtmed.

Oliveira, P. M. A. (2003). Animais silvestres e exóticos na clínica particular (Vol. 375). Roca, Brasil.

Pachaly, J. R. (2000). Principais drogras empregadas na contenção farmacológica dde animais silvestres. Arquivos de Ciências Veterinárias e Zoologia Da UNIPAR, 3(1), 87-94.

Píparo, L. J. (2007). Particularidades cirúrgicas em répteis. Anais Da III Jornada Grupo Powler: Encontro Nacional de Medicina de Répteis., 195-208.

Rauber, A., \& Silva, D. F. (2020). Contenção física em aves e répteis silvestres. Revista Thêma et Scientia, 10(2), 264-273.

Rodrigues, T. O., Santos, A. L. Q., Pereira, P. V. R., Siqueira, S. E., Rodrigues, T., \& Guimarães, E. C. (2018). Uso de cetamina pela via cólon-retal para contenção química de jiboias Boa constrictor Linnaeus, 1758 com teste de influência da droga sobre o sistema renal. Pesquisa Veterinária Brasileira, 38(2), 328-334. DOI: https://doi.org/10.1590/1678-5150-pvb-4637

Rubel, A.; Kuoni, W. \& Frye, L. 2007.Radiologia e Imagem. Anais da III Jornada Grupo Powler: Encontro Nacional de Medicina de Répteis. Curitiba-PR: 283-296.

Santos, A. L. Q., Oliveira, S. R. P., Kaminishi, A. P. S., 2002, M. B., Menezes, L. T., Souza, R. R., Ferreira, C. H., Nascimento, L. R., \& Moraes, F. M. (2012). Avaliação do uso da combinação de propofol e midazolam na contenção farmacológica e anestesia do cágado-de-barbicha Phynops geoffroanus Schweigger, 1812 (Testudines, Chelidae). PUBVET, 6(12), 1331-1337. DOI: https://doi.org/10.22256/pubvet.v16n12.1337

Sawyer, D. (2008). The practice of veterinary anesthesia: small animals, birds, fish and reptiles. CRC Press.

Schumacher, J. (2007). Chelonians (Turtles, tortoises and terrapins). In G. West, D. Heard, \& N. Caukett (Eds.), Zoo animal and wildlife immobilizations and anesthesia. Blackwell Publishers Inc.

Stuart, J. B. A. P. (2017). Descrição do sistema respiratório do jabuti-piranga (Chelonoidis carbonaria, Spix, 1824): aspectos radiográficos, tomográficos e anatômicos. Universidade Estadual Paulista.

Universidade de Évora. 2011. Anestesia Geral em Animais de Companhia. Texto de apoio às aulas práticas de anestesiologia do curso de medicina veterinária da Universidade de Évora. Universidade de Évora, Potugal.

Histórico do artigo:

Recebido: 28 de março de 2021. Aprovado: 13 de maio de 2021.
Licenciamento: Este artigo é publicado na modalidade Acesso Aberto sob a licença Creative Commons Atribuição 4.0 (CC-BY 4.0), a qual permite uso irrestrito, distribuição, reprodução em qualquer meio, desde que $\mathrm{o}$ autor $\mathrm{e}$ a fonte sejam devidamente creditados. 